\title{
Comunicação
}

[Communication]

\section{Contaminação por Salmonella spp. em uma cadeia de produção de ovos de uma integração de postura comercial}

\author{
[Salmonella contamination in an egg production chain of a laying hens integration]
}

\author{
L.B.M. Kottwitz ${ }^{1}$, A. Back ${ }^{2}$, J.A. Leão ${ }^{2}$, I. Alcocer ${ }^{1}$, M. Karan ${ }^{3}$, T.C.R.M. Oliveira ${ }^{1}$ \\ ${ }^{1}$ Universidade Estadual de Londrina - Londrina, PR \\ ${ }^{2}$ Centro de Diagnóstico Veterinário Brasil Sul Ltda - Cascavel, PR \\ ${ }^{3}$ Secretaria da Agricultura e do Abastecimento - Cascavel, PR.
}

\begin{abstract}
A salmonelose é uma zoonose de grande importância e apresenta-se como um desafio para a saúde pública, em razão da elevada endemicidade, alta morbidade e, acima de tudo, pela dificuldade do seu controle (Hofer et al., 1997). Nas últimas décadas, aumentou a incidência de salmonelose humana causada pelo sorovar Enteritidis. Os veículos mais freqüentes de contaminação têm sido os ovos e a carne de aves e seus derivados. Em geral, a manipulação inadequada durante o preparo de alimentos é um fator importante de contaminação cruzada (Téo, 2002). Segundo Okamura et al. (2001), a capacidade de transmissão transovariana e horizontal de $S$. Enteritidis para ovos resultou em ampla disseminação e persistência desse sorovar na indústria avícola.
\end{abstract}

No Brasil, poucos são os levantamentos sobre a presença de Salmonella em ovos comerciais (Langoni et al., 1995). No estado do Paraná, ocorreram 217 surtos de salmonelose no período de 1999 a 2004, sendo que o sorovar Enteritids foi identificado em $87,0 \%$ e $89,8 \%$ das cepas isoladas de pacientes e de alimentos envolvidos nesses surtos, respectivamente. A constatação de que $47,0 \%$ dos surtos ocorridos nesse período foram causados por alimentos elaborados à base de ovos evidencia o risco potencial que esse alimento pode representar para a saúde pública (Alcocer, 2004). Embora o ovo apareça como o alimento mais envolvido nos casos de salmonelose ocorridos no Paraná, os dados sobre os sorovares e fagotipos prevalentes são escassos e, geralmente, obtidos por informações extraoficiais, já que pouco tem sido publicado (Téo, 2002).

Este trabalho teve como objetivos avaliar a contaminação por Salmonella spp. em uma cadeia de produção de ovos de uma integração de postura comercial e realizar a sorotipagem das cepas de Salmonella spp. isoladas.

As amostras analisadas constituíram-se de material biológico de aves e de ovos destinados ao consumo humano. As amostras foram coletadas entre abril e agosto de 2004, em uma cooperativa com integração de postura comercial, de 150.000 poedeiras ISA BROWN, distribuídas em 30 granjas, com idade entre 17 a 76 semanas. Essas amostras corresponderam a $2 \%$ das aves e foram obtidas a partir da coleta de um "pool" de fezes de 100 aves e um "pool" de 50 suabes de cloaca. Cada suabe correspondeu à amostragem de duas aves. Das granjas com isolamento de Salmonella spp. foram coletados 250 ovos, que corresponderam a $5 \%$ da produção diária de cada granja.

Foram analisadas 60 amostras de fezes e 3.000 suabes de cloaca, de acordo com o preconizado pelo Ministério da Agricultura, Pecuária e Abastecimento (Brasil, 1995). A pesquisa de

Recebido em 18 de julho de 2006

Aceito em 3 de abril de 2008

Endereço para correspondência (corresponding address)

Rua Santa Catarina, 245/42 - 85801-040 - Cascavel, PR

E-mail: lukottwitz@yahoo.com.br 
Salmonella spp. dos 3.000 ovos foi realizada, primeiramente, da água peptonada $1 \%$ utilizada na lavagem superficial das cascas dos ovos e, posteriormente, das gemas, de acordo com o preconizado pela AOAC (Official ..., 1995).

Salmonella foi isolada em oito $(23,0 \%)$ das 30 granjas analisadas. Percentagens mais altas foram encontradas por outros autores, porém o número de granjas analisadas foi menor. Gama (2001) detectou Salmonella em quatro $(33,3 \%)$ dos 12 lotes de galinhas poedeiras de variedade branca leve analisadas, enquanto Henzler et al. (1998) verificaram a presença dessa bactéria em $30,0 \%$ dos 60 lotes analisados. Rodrigues (2002), ao avaliar 360 suabes de cloaca de seis granjas de postura comercial, isolou Salmonella em três granjas, caracterizando $50,0 \%$ dos lotes avaliados.

Entre os sorovares identificados nas granjas contaminadas, Salmonella enterica subsp. enterica $(\mathrm{O}: 3,10)$ foi o sorovar mais isolado $(67,0 \%)$. Os sorovares Mbandaka, Infantis e Newport corresponderam, cada um, a $11,0 \%$ dos isolados, e $S$. Enteritidis não foi isolada.

Os dados epidemiológicos disponíveis no Paraná indicam que Salmonella Enteritidis foi responsável pela maioria dos surtos de salmonelose humana ocorridos nesse estado, incluindo a área de abrangência das granjas estudadas. Os produtos à base de ovos foram associados a 47,4\% dos referidos surtos (Alcocer, 2004). Pelos resultados obtidos, é possível supor que o plantel das granjas da integração de postura comercial analisado esteja isento desse patógeno. Porém, outros aspectos podem ter contribuído para o não isolamento de $S$. Enteritidis. Os mais importantes referem-se à possibilidade de eliminação intermitente do microrganismo e às diferenças genéticas de suscetibilidade das aves às doenças.

Embora com freqüência menor, foram isolados outros sorovares citados como responsáveis por casos e surtos de salmonelose humana no Brasil e no exterior, muitos deles envolvendo alimentos de origem avícola. A sorotipagem de cepas de Salmonella spp. associadas a surtos de doenças transmitidas por alimentos no estado do Paraná, no período de 1999 a 2004, mostrou que os sorovares Newport e Mbandaka representaram
$5,0 \%$ e $0,60 \%$ dos isolados dos pacientes, respectivamente, e o sorovar Infantis, $1,9 \%$ dos isolados de alimentos (Alcocer, 2004).

Jakabi et al. (1999), ao avaliarem dados de 18 surtos alimentares de Salmonella spp. ocorridos em São Paulo, no período de 1994 a 1997, constataram a presença de $S$. Infantis em maionese e batata cozida. A observação de alimentos diferentes relacionados ao mesmo surto e apresentando o mesmo sorovar permitiu concluir que a manipulação inadequada durante o preparo de alimentos é também um fator importante de contaminação.

Nas granjas onde houve isolamento de Salmonella spp., foi realizada a coleta de ovos e a análise da água de lavagem da superfície da casca e análise da gema. Independente do método, não houve isolamento de Salmonella spp. Um fator a considerar para o não isolamento de Salmonella é a intermitência de eliminação e de transmissão vertical (Tizard, 1992). Além disso, a taxa de isolamento de Salmonella em ovos produzidos por aves artificial ou naturalmente infectadas sofre influência de fatores, como tamanho do lote, número de ovos examinados e maneira pela qual os ovos foram colhidos (Gama, 2001).

$S$. Enteritidis, que é o sorovar mais associado a salmonelose humana no Paraná, não foi isolado tanto dos ovos como das granjas positivas. Como foram analisados 3000 ovos, acredita-se que os ovos inspecionados e previamente higienizados pela cooperativa estudada oferecem baixo risco à saúde pública. Entretanto, como produtos à base de ovos têm sido responsáveis por quase $50 \%$ dos surtos de salmonelose ocorridos nos últimos anos no Paraná, é necessário considerar o mercado "informal" de ovos de descarte. Embora seja proibida no Brasil, a venda desse produto é uma realidade na região onde este trabalho foi realizado. Ovos caipira produzidos por pequenos produtores sem a higienização necessária e muitas vezes com a reutilização de embalagens precisariam também ser considerados. Assim sendo, são necessários estudos mais amplos para determinar de maneira mais conclusiva quais ovos têm participação na epidemiologia da salmonelose humana no Paraná.

Palavras-chave: ovo, Salmonella, contaminação 


\begin{abstract}
Contamination of ISA BROWN layer hens by Salmonella spp. and serotyping of the isolated strains were performed in 30 farms. Salmonella detection was done from feces and cloaca swabs. Eggs produced in the farms contaminated by Salmonella spp. were analyzed by culturing the shell rinsing and egg yolk. Salmonella spp. was isolated in eight (23.0\%) farms, but was not detected from eggs. S. Enteritidis, which is the most prevalent sorotype associated to human salmonelosis in Paraná State, was not isolated either from birds or eggs analyzed. The sorotypes isolated were Salmonella enterica subsp. enterica (0:3.10) (67.0\%), Mbandaka (11.0\%), Infantis (11.0\%), and Newport (11.0\%).
\end{abstract}

Keywords: egg, Salmonella, contamination

\section{REFERÊNCIAS BIBLIOGRÁFICAS}

ALCOCER, I.R. Sorotipagem, Fagotipagem, Caracterização Molecular de Cepas de Salmonella spp. e Avaliação Epidemiológica de Surtos Ocorridos no Paraná de 1999 a 2004. 2004. 216f. Tese (Doutorado) - Universidade Estadual de Londrina, Londrina, PR.

BRASIL. Ministério da Agricultura, Pecuária e Abastecimento. Secretaria de Defesa Agropecuária. Portaria $\mathrm{n}^{\circ} 126$, de 06 de novembro de 1995. Normas para diagnóstico das salmoneloses aviárias. Anexo I - Descrição das técnicas/métodos bacteriológicos e sorológicos para diagnóstico das salmoneloses aviárias $(S$. Enteritidis, $S$. Gallinarum, $S$. Pullorum e $S$. Typhimurium). Diário Oficial da República Federativa do Brasil, Brasília, DF, 06 nov.1995, Seção 1, n.212, p.17694-17698.

GAMA, N.M.S.Q. Salmonella $s p$. em aves de postura comercial. 2001. 59f. Dissertação (Mestrado) - Universidade Estadual Paulista, Jaboticabal, SP.

HENZLER, D.J.; KRADEL, D.C.; SISCHO, W.M. Management and environmental risk factors for Salmonella enteritidis contamination of eggs. Am. J. Vet. Res., v.59, p.824-829, 1998.

HOFER,E.; SILVA FILHO, S.J.;REIS, E.M.F. et al. Prevalência de sorovares de Salmonella isolados de aves no Brasil. Pesq. Vet. Bras., v.17, p.55-62, 1997.

JAKABI, M.; BUZZO, A.A.; RISTORI, C.A. et al. Observações laboratoriais sobre surtos alimentares de Salmonella spp. ocorridos na Grande São Paulo, no período de 1994 a 1997. Rev. Inst. Adolfo Lutz, v.58, p.47-51, 1999.

LANGONI, H.; PRADO, R. A. T.; PINTO, J. P. A. N. et al. Isolamento de salmonelas em ovos de galinha oferecidos no comércio de Botucatu SP. Rev. Hig. Alim., v.9, p.45-47, 1995.

OFFICIAL methods of analysis. Microbiological methods. Washington: AOAC, 1995. Chapter 17.

OKAMURA, M.; $\quad$ KAMIJIMA,Y; MIYAMOTO, T. et al. Differences among six Salmonella serovars in abilities to colonize reproductive organs and to contaminate eggs in laying hens. Avian Dis., v.45, p.61-69, 2001.

OLIVEIRA, D.D.; SILVA, E.N. Salmonela em ovos comerciais: ocorrência, condições de armazenamento e desinfecção da casca. Arq. Bras. Med. Vet. Zootec., v.52, p.655-661, 2000.

RODRIGUES, L.B. Levantamento sorológico e detecção de Salmonella em granjas de postura comercial de pequeno porte em um município do Estado do Rio Grande do Sul. 2002. 88f. Dissertação (Mestrado) - Universidade Federal do Rio Grande do Sul, Porto Alegre, RS.

TÉO, C. R.P.A., Avaliação epidemiológica dos surtos de salmonelose ocorridos no paraná entre janeiro de 1999 e junho de 2001. 2002. 101f. Dissertação (Mestrado) - Universidade Estadual de Londrina, Londrina, PR.

TIZARD, I. Veterinary immunology: an introduction. 4.ed. Philadelfia: Saunders, 1992. $531 \mathrm{p}$. 